\title{
Universal Design for Learning as a Tool for Inclusion in the Higher Education Classroom: Tips for the Next Decade of Implementation
}

\author{
Frederic Fovet \\ School of Education and Technology, Royal Roads University, Victoria, Canada
}

\section{Email address:}

Frederic.fovet@royalroads.ca

\section{To cite this article:}

Frederic Fovet. Universal Design for Learning as a Tool for Inclusion in the Higher Education Classroom: Tips for the Next Decade of Implementation. Education Journal. Special Issue: Effective Teaching Practices for Addressing Diverse Students' Needs for Academic Success in Universities. Vol. 9, No. 6, 2020, pp. 163-172. doi: 10.11648/j.edu.20200906.13

Received: August 8, 2020; Accepted: October 15, 2020; Published: December 8, 2020

\begin{abstract}
Universal Design for Learning (UDL) has gained significant momentum in Higher Education (HE) over the last decade in North America. It offers considerable potential to achieve the inclusion of diverse students in the HE classroom. It is a unique approach, first because it shifts the instructor mindset away from medical model practices, and second because it allows the development of inclusive practices that address the needs of the full spectrum of diverse learners. As a result of this growing interest, there have been implementation efforts within a wide range of disciplines and settings in post-secondary education. The time has come, however, to identify the challenges that remain, to seek appropriate solutions, and to develop strategic direction to shape UDL adoption for the next decade. This paper draws on phenomenological data collected by the author on his own practice through a process of auto-ethnography. This data emerges from three dimensions of the author's practice: his past role as manager of an accessibility unit, as well as his current role as UDL consultant within HE, and faculty member exploring UDL in his own teaching. The chapter identifies remaining challenges, explores solutions, and frames a vision for what UDL development might look like in HE over the next decade.
\end{abstract}

Keywords: Universal Design for Learning, Inclusion, Higher Education, Accessibility Services, Teaching and Learning, Diverse Learners

\section{Introduction and Context}

Universal Design for Leaning (UDL) has taken great strides within Higher Education (HE) over the last decade in North America [1] and Europe [2]. It has established itself as a convenient and sustainable framework for the inclusion of students with disabilities in the post-secondary classroom [3]. It does so without relying on medical model approaches and, instead, encourages instructors to adopt a design mindset that is focused on the user experience (UX). As such it has shown promise not just with respect to students with disabilities, but also when it comes to the inclusion of International students [4], Indigenous students [5], and first generation students [6]. While the benefits of UDL in HE have become increasingly obvious, the push for UDL implementation has nonetheless come to a stall in many ways. Scholars and advocates have gone through a first exciting wave of curiosity, but there remains a lot of answered questions with regards to the sustainable, whole campus implementation of UDL across disciplines. This paper explores phenomenological data collected by the author through several years of UDL advocacy in HE. This phenomenological data is analyzed so that it may yield a conceptual map of the work that is required to lead UDL implementation into the next decade. In many respect it is therefore preoccupied with the strategic dimension of UDL implementation across campuses.

\section{Literature Review}

\subsection{What Is UDL}

UDL has emerged from a concept called Universal Design (UD) which was developed by the field of architecture in the 1970s [7]. Architects started challenging the profession's obsession with aesthetics in the design of building, and 
highlighted that as a result these buildings, while pleasant to the eye, often did not meet the needs of the persons living or working in them [8]. As a result there would often be a need for retrofitting to make them usable or inhabitable. These UD advocates asserted design in architecture and products should be primarily focused instead on the user experience (UX) [9]. They argued that inclusive design needs to prioritize the needs of the user over aesthetic preoccupations, and this led them to create UD guidelines [10].

UDL advocates have grounded their work on this reflection on design and shifted the principles to the classroom [11]. Using research from the field of neuroscience, they highlight the fact that learning is extremely diverse as a task and varies not just between individuals, but even within the experience of a single person, sometimes through a single day - depending on context and circumstances [12]. As a result, these scholars argue, full accessibility in learning can only be achieved when an optimal degree of choice in injected into teaching and learning. Learners are then able to work from a strength-based position, understanding their needs and preferences, and choosing among options to demonstrate learning in the best possible format [13].

The scholarship on UDL has traditionally categorized learning around three essential dimensions: input (the way student are offered information and resources), output (the way students contribute, participate, and create content), and engagement (the student's affective connection with the content of the instruction). Learners are diverse within each of these three functions of the brain and it will therefore be important for instructors to offer as much flexibility as possible within each of these axes of design [14]. This task which consists in optimizing flexibility in design within each of these dimensions of learning is guided within the framework of UDL by three overarching principles: multiple means of representation, multiple means of action and expression, and multiple means of engagement [11].

These principles of course often overlap and they are just a crude representation which encourages the educator to consider the three dimensions that require flexibility and inclusive design. Importantly, unlike differentiation, UDL is not carried out in the moment. It is a design process and therefore does not happen in the class but rather in the moments when the instructor has the opportunity to return to the blue print and to alter the design of instruction or assessment. This is a feature which makes UDL particularly appealing within HE, as instructors often feel that with limited face to face time with the learner, large classes and short semesters, it is impossible for them to differentiate instruction in the moment once they are in class. They also often feel that they lack the skills to identify the specific needs of the learner. UDL does not impose a diagnostic lens on exceptionality, and instead presupposes that there is great learner diversity in any lecture hall. Implementing UDL is also not an overnight process. Redesigning delivery and assessment is time consuming and this should be seen as a life-long reflection on practice, rather than a quick and instantaneously shift.

\subsection{UDL in Higher Education}

UDL was originally mostly visible and discussed in the K-12 sector [15]. Over the last decade it has, however, also gained significant interest from the HE sector [16]. It has been mostly thus far been explored and implemented in undergraduate courses. As stated previously, UDL is immediately attractive to $\mathrm{HE}$ instructors because it seems much more practical than differentiation when it comes to implementing inclusive measures in the lecture hall. It provides clear, hands-on principles for inclusive design which can be used with ease by instructors. In this sense it very much demystifies the process of proactively designing inclusively for the classroom [7]. It also enables universities to reduce pressure on accessibility services by demonstrating to instructors that most students' needs can be accommodated in class with simple inclusive design strategies [17].

UDL implementation in HE is not, however, entirely straightforward and the process of cross-campus integration and development has faced significant hurdles. While the benefits of UDL in instruction are clear, it is necessary to realize that management of change in the post-secondary sector is complex and fraught with inherent difficulties. This is, after all, an environment which is, from an organizational point of view, multilayered, complex, anchored in tradition and historical hierarchy [18]. It also employs people possessing widely varying backgrounds, trainings, qualifications, and theoretical perspectives. It is also an environment that is unionized [19]. All these variables place considerable strains on the process of UDL implementation and it must be seen and planned as a long tortuous journey rather than a brief overnight transformation. Careful strategic planning will have to accompany the introduction of UDL on campuses, or else it risks taking off with the momentum of curiosity but quickly also being dismissed and ignored [20]. A lesson which has been learnt over the last decade is that the adoption of ecological theory as a lens greatly benefits this process, and allows stakeholders to grasp its complexity and plan accordingly.

\subsection{Successes to Date}

A UDL had gained traction in many community colleges, where it is generally felt it has great potential in addressing the needs of non-traditional students in what is increasingly a multi-age classroom [21]. It has also shown to be successful when it comes to creating inclusive provisions for students in Arts and Humanities undergraduate courses [22]. There has more recently been emerging literature addressing the use of UDL in science courses but this is still of very limited scope at this stage and it is clear further scholarship in this area is urgently required. Importantly, the interest for UDL in HE has looked beyond impairment and disability, and established early on that it had benefits for all learners [23]. There has overall been a high degree of visibility around UDL emerging from accessibility services and these have, as a rule, been involved in the introduction and development of UDL on most North American campuses [24]. A development which is 
important to note is that UDL has allowed for international exchanges and discussions around inclusion in the post-secondary sector, between campuses across borders, particularly between North America and Europe; UDL has served as common language in these international networking [25]. Lastly UDL has positioned itself as the only framework for inclusion which aligns itself with principles of sustainability [26]. It indeed reduces pressure on accessibility services, allows the majority of students' needs to be addressed in the classroom itself, and reduces overall costs while transforming pedagogy.

\section{Methodological Reflection}

The article adopts a phenomenological perspective [27] and presents data collected by the author, over the last decade, around his lived professional as a UDL advocate, a UDL consultant, and a faculty member seeking to implement UDL and to implement colleagues in this process. The author held various roles which involved promoting the use of UDL in HE over the last decade and the paper analyzes this various experiences from a phenomenological stance. He has been a UDL advocate promoting the framework in professional development forums; he has also been a consultant working closely with post-secondary institutions on their process of implementation. Finally he is also a faculty member and long adopter of UDL who endeavours to implement it in his own practice and seeks to support colleagues through the same reflection. Phenomenological data from all three of these perspectives and lived professional experiences is used and analyzed within this paper in a format of auto-ethnography as methodological tool [28].

\section{Findings}

Findings are presented and categorized in a way that highlights which suggestions are more pressing, and which ones are longer term.

\subsection{Promising Classroom Practices that Require Urgent Attention}

For the sake of ease and conceptual clarity, the outcomes perceived as requiring immediate attention will be categorized using the three principles of UDL as respective axes for reflection [29].

\subsubsection{Multiple Means of Representation}

When it comes to the 'multiple means of representation', authors and practitioners have mostly focused on the accessibility of resources and class material through the lens of impairment. The struggle has thus far been to support instructors as they develop awareness around the barriers that print creates for many students [30]. The work therefore often focuses on providing instructors with professional development around the need for accessible documents which can be read with reading software [31]. It has also meant developing know-how among faculty around the issues of web accessibility so that online resources used meet web accessibility standards [32]. These days, most information and resources offered to students, are presented via a Learning Management System (LMS), whether the course is offered face to face or online [33]. The way we use these LMSs to provide students with information needs to be re-examined through a UDL lens.

Rather than use the LMS as a mere depository of material it is essential that faculty begin to see these platforms as tools for the inclusion of diverse learners. UDL will encourage them to consider optimizing flexibility in the resources they use to support their teaching, and over the next decade it is hoped the material that is loaded to LMSs will become increasing diversified. As an instructor engages with this UDL principle, it should become crucial to offer not just one source, but sources of varying degrees of complexity, length, level of language, theoretical density [34]. This will offer and support multiple pathways into the material for all diverse learners, including students with disabilities, International students, Indigenous students and first generation post-secondary students $[35,23]$.

\subsubsection{Multiple Means of Action and Expression}

Much of the work carried out thus far within UDL implementation, with regards to multiple means of action and expression has been centered on diversification in assessment $[36,37]$. It has been very important work in an environment where differentiation is not popular and does not represent a systematic best practice. When looking at the future, however, it is perhaps time now for the work on UDL, with regards to action and expression, to go a little further than assessment and to consider deeper pedagogical transformation.

This UDL principle indeed connects well with the wider concept of digital literacy [38], and will enable instructors to transform their vision of the learner till they are fully seen and perceived as 'producer of content and message'. Integrating the UDL principle of 'multiple means of action and expression' supports instructors as they reshape delivery to give increasing space and freedom to develop an identity as creator of content. This means the learner is less likely to be placed in a passive role of listener, and instead will be offered choice and flexibility in how they contribute to the very content and canvas of the course. This may take the shape of e-portfolios, of co-teaching, experiential tasks, of project-based learning or enquiry based learning [39, 40].

A rich and authentic reflection by instructors around this UDL principle will inevitably lead them to an engagement with co-construction as an innovative and transformative approach with students [41, 42]. The UDL discourse will need to more explicitly welcome and nurture this reflection on co-construction. It will assist instructors navigate some of the tension they may feel around co-creation. Some faculty indeed are fearful of co-creation because it involves relinquishing a degree of control within the classroom [43]; others may be reluctant to embrace curriculum co-creation because it represents a lot of work and specific deign challenges; some instructors may also feel the current 
neo-liberal pressures on productivity create tension that pushes them away from more creative pedagogy [44]. This UDL principle offer instructors hands on guidance, from a design perspective, when considering curriculum co-creation; it encourages them to begin the journey with curriculum co-creation from the angle of accessibility; it reassures them of both the feasibility and urgency of this approach with students. UDL, over the coming decade, needs to embrace this role, and serves as a tool to support the implementation of curriculum co-creation in HE.

\subsubsection{Multiple Means of Engagement}

This UDL principle is perhaps the most tricky when it comes to implementation. Most HE instructors indeed will be quick to assess they are focused on learner engagement [45, 46]. Learner engagement has become almost a buzz word within HE Teaching and Learning, but it can remain quite shallow as a concept $[47,48]$. UDL encourages instructors to, not just focus on engagement, but more importantly consider the extent to which their construction of engagement - and associated expectations - are ethnographic [49, 50]. The instructor will then use inclusive design principles to inject flexibility in this conception of engagement they might have originally had in order to arrive at a new concept entirely: more flexible, more learner-centered, and more authentic.

This process of reflection, if it seeks to be rich and genuine, will need to examine how the classroom activities connect with the learners' lived experience and genuine interests. In this sense UDL is increasingly drawn to examine and explore its overlap with Critical Pedagogy. Critical Pedagogy argues that teaching and learning must be rethought in order to support the learner out of a state of passivity towards a role as active participant in a dialogical process of awareness creation around inequitable power dynamics [51]. There will be many opportunities to integrate the scholarship on Critical Pedagogy into an exploration of this UDL principle. At present, however, this reflection around the commonalities of both scholarships is sorely missing [52]. One of the urgent calls for action for the next decade will be an increased awareness of Critical Pedagogy as serving the reflection around engagement under a UDL lens.

\subsection{Need for Discipline Specific Literature}

Apart from promising UDL practices that need to be further developed within HE over the next decade, there are other pressing needs that UDL advocates need to consider in order to ensure cross-campus implementation efforts are successful. One of the priorities expressed as urgent within the field is the need for UDL literature and scholarship which meets the specific and current needs of the field.

\subsubsection{Expectations with Regards to Scholarship on Hands-on Application in the Classroom}

One such pressing need relates to the desire expressed by instructors for scholarship that considers the hands-on implementation of UDL in the classroom. Thus far, much of the literature on UDL has been broadly focused on highlighting the benefits of the use of UDL [53]. This has been useful in the initial and exploratory process of discovery of UDL the post-secondary sector has been engaged in over the last decade. This now frustrates practitioners, however, and instructors are eager to have access to scholarship that explains, describes, and analyzes what UDL might look like in the classroom when successfully and systematically applied [54]. One of the difficulties is that UDL remains a lens on practice, rather than a checklist. The process of applying UDL in the classroom is therefore less about listing classroom tips, and more about carrying out an in-depth and rich reflection on learner diversity within the design of delivery and assessment. This said, without providing readily applicable and generic strategies, it is possible for UDL literature to describe this process of reflection from the phenomenological perspective of instructors who have engaged with this process. It is therefore likely - and hoped - that an emerging body of literature will appear in the coming decade and offer instructors a more detailed and complete picture of what pedagogy for the 21 st century might look like once UDL is being applied with intent [55].

\subsubsection{UDL in Laboratories}

The field is particularly keen to see the scholarship on UDL tackle specific teaching contexts, environments for teaching and learning that are more diverse than the traditional lecture hall. There is currently a great paucity of literature related to the application of UDL in labs [56, 57]. These could be science labs, but could also include language labs. Labs represent a specific challenge for practitioners engaged in a reflection around UDL implementation. Offering multiple means of representation in lab environment is not simply about offering digital media and reducing the reliance on print. Accessibility has to be thoroughly examined within the various interactive dimensions the lab environment offers to the student $[58,59]$. Applying UDL in this space is possible, but it requires a detailed, environment specific reflection that has not been so far been highlighted by the literature.

\subsubsection{UDL in Trades}

UDL, this far, has remained conspicuously absent from the literature on learner diversity in trades education [60]. There are specific challenges to discussing multiple means of representation, or multiple means of action and expression, in a post-secondary classroom which may be taking place within a construction site, a mechanical repair shop, or a deep-sea dive operation site [61]. There are in fact communities of practice and promising UDL project within trade programs in HE [16], but most of these initiatives have yet to be reported in formal research publications. Trade programs have the advantage of overlapping between traditional lecture hall teaching and real world employment conditions. The fields of employment and industry are increasingly considering the application of UDL [62], and trade schools will represent a prime environment for brainstorming around what UDL might look like outside the classroom. The post-secondary classroom is increasingly also seeking to integrate principles of Experiential Learning [63]. Trade schools will, over the 
coming decade, represent a microcosm within which HE as a sector will be able to consider the implementation of UDL to environments that are more diverse than the traditional lecture hall [64].

\subsubsection{UDL in Studio Arts}

There has been interest around the implementation of UDL in studio based arts instruction [65-67], but there is thus far little literature that documents this reflection. It is hoped that over the next decade this will be remedied, and that practitioners in the field of visual arts education will produce a body of literature that offers a phenomenological analysis of the processes they are engaged in with regards to UDL implementation in studio space. There are very specific variables within studio based instruction that make ready-made, generic UDL strategies impossible to implement without further reflection. Offering students flexibility with deadlines and time is indeed tricky, as often studio-based instruction involves weekly critique activities [68, 69]; students become incapable of offering their work for studio critique when their submission timelines varies from that of other students. UDL principles will therefore need to be specifically devised for studio-based arts instruction.

\subsection{Importance of Ecological Theory in Strategic UDL Implementation}

Another angle of UDL implementation in HE which needs to take a new dynamic direction over the next decade is the investigation of effective strategic models for systemic, cross-campus implementation. As previously discussed, UDL has been mostly discussed within HE in terms of academic benefits and potential for the inclusion of diverse learners [53]. There has been very little literature focused on the organizational dimensions of UDL implementation [20]. While the appeal of UDL grows, many practitioners and institutions find themselves stalled, and disempowered in the face of hurdles, because there has been no significant reflection around management of change on an institutional scale. As a result, initial efforts often lose momentum, individual advocate burn out, and UDL implementation efforts fail to deliver the expected results. These represent significant concerns that compromise the long term implementation of UDL in HE, and it is therefore essential for researchers and scholars to focus on these strategic issues over the next decade, in order to create a strong and convincing scholarship on the topic of UDL and management of change.

It is becoming increasingly clear that one of the issues which hinders the development of UDL across campuses is the fact that management of change has so far been conceptualized in a unidimensional and slightly reductionist manner. The presumption has been that if the various stakeholders (senior administrators and faculty) were made aware of the potential benefits of UDL, implementation would flow from this initial curiosity. Instead, it is important to acknowledge that HE institutions are complex, multi-layered environments made up of professionals from various backgrounds with a variety of training [70-72]. Often the theoretical positioning of these stakeholders varies widely. It is also usually a unionized environment [73]. It will therefore be important to adopt ecological theory as an overarching theoretical lens in order to fully acknowledge and integrate the multiple variables that are likely to affect a process of management of change in HE [20].

\subsection{Making UDL Explicitly Relevant to International Students and to Indigenous Students}

The last decade has shown the relevance of UDL for all learners in the post-secondary sector [54]. In the coming years, it will now be time, however, to highlight and develop even more explicitly the immediate impact UDL can have for International students and Indigenous students. One of the important shift in mindset, indeed, which has become possible with the use of UDL is a movement away from a diagnostic approach - that applied a deficit lens when considering the learner - towards a simple hands-on analysis instead of the barriers created by the design of the environment. The interesting observation which is becoming apparent in the literature is that the barriers that students with disabilities face in the design of instruction and assessment, are often the same as those faced by International students and Indigenous students [74-76]. They too have, up to now, been considered and dealt with by the post-secondary sector through a deficit lens and UDL will remedy this very swiftly. As soon as instructors start engaging with UDL, indeed, they become conscious of the fact that it is their design - and not the characteristics of the learner - which become problematic in the HE classroom.

It will become important over the next decade that first the UDL discourse within HE integrates effectively the perspective of International and Indigenous students. It is urgent too that support services that are assisting students with disabilities, International students and Indigenous students communicate effectively and find a common discourse around the need for inclusive pedagogy. UDL will act as a cement in the creation of this common discourse. Thirdly it will be crucial that instructors are made aware of the relevance of UDL to these three populations of students, and conscious of the fact that all three groups share common experiences with barriers in access to learning. It is indeed easy for faculty to dismiss the concerns of students with disabilities and their advocates as being a 'minority discourse' best addressed by accessibility services, but it becomes now difficult to ignore these concerns and these demands for inclusive teaching if one tallies up the numbers between the three groups. They clearly now represent a significant percentage of any campus' student population and are producing what is very much now a 'majority' discourse in terms of their challenges and the solutions they seek to see put in place.

\subsection{Pressing Need to Examine the Potential of UDL in Graduate Education}

In the last few years UDL has attracted considerable interest, and led to implementation efforts of significant scope, but 
always within Undergraduate education (UE). There seems to be a perception currently that UDL as a framework is more suited to UE than the Graduate education (GE). There are many reasons for this perception. First it is often assumed that class sizes are small, the relationship between student and instructor much more developed, and that faculty are therefore more easily able to address accessibility issues directly in a seamless manner. This could not in fact be further from the truth and there are as many if not more accessibility issues in GE [77]. UDL therefore has an immediate, tangible and powerful impact within Graduate programs as well.

A second reason why this misperception persists is that it is perhaps assumed that by the time students get to graduate school, they have completed an Undergraduate degree, and have by then adapted to the specific demands of the post-secondary sector. It is thought by many that students entering graduate programs will have developed, over the course of their first degree, effective strategies which will reduce the needs for inclusive pedagogy or accommodation. Again data from accessibility services show that this is a myth [78]. Many graduate students struggle and it will be crucial therefore for faculty to consider UDL with a view to reducing barriers, particularly barriers which create or exacerbate Mental Health issues among students.

It is also argued by some practitioners and scholars that the student population in GE is much more homogeneous and therefore no longer requires differentiation strategies. This is a misguided construct since the internationalization of HE has been most noticeable in the Graduate sector. The Graduate classroom has in fact, as a result, never been more diverse than now [79]. The traditional accommodation based approach is ineffective with regards to this diversity. International graduate students are statistically indeed less likely than others to come forward for services. UDL will be particularly well suited to address the needs of these students as the implementation of inclusive design means there is less reliance on accessibility services [74].

\subsection{Pressing Need for Change in the Current UDL Advocacy Model for a Rethink around Ownership}

Up to this point, it has been mostly accessibility services that have been responsible for the development of UDL and advocacy around implementation on post-secondary campuses [49]. This responsibility has fallen to them historically since UDL was originally understood to be mostly useful for students with disabilities. Now that we appreciate this is not the case, however, it becomes counter-intuitive for accessibility services to continue to be seen as having ownership over the framework. Instead a concerted degree of reflection must occur on each campus in order to determine which key stakeholders should be involved in UDL work. These are likely to include Teaching and Learning units, support services for Indigenous students, and support services for International students. It could also include instructional designers when these are present on the campus in question. The specific stakeholders who need to become involved will depend from campus to campus, and once again an ecological lens should be applied to acknowledge the full complexity of the task at hand [20]. It is pressing that over the coming years, this shift in strategy occur as accessibility services themselves have shown to be significantly ambivalent about UDL. In many cases indeed, the service provision model is so anchored into medical model practices that this makes them the least likely ambassadors for UDL practices. Add to this the fact that accessibility services personnel are often extremely anxious to discuss pedagogy with faculty, and the irony of making them lead UDL implementation work becomes readily apparent.

\subsection{Focus on UDL Implementation in the Global South}

A further development is desirable over the next decade: it would seem important in a context of decolonizing the academy, to see more focus on UDL implementation in the Global South. The UDL movement has been uncomfortably blind to Global North-Global South power dynamics within an International context [80]. There has been very little scholarship on UDL in developing countries [25], and UDL scholars can at this point be accused of outright ignoring the global dimension within the field of education. If this shift does not occur relatively quickly, the UDL movement is likely to be criticized for not embracing key notions of critical theory - which in fact align remarkably well - around privilege, power, post-colonialism [81]. The UDL discourse of the next decade in HE must systematically acknowledge the Global North- Global South dichotomy and be more preoccupied with integrating and amplifying voices from the south.

\section{Outcomes}

Beyond the recommendations formulated above for a new decade of UDL work, there are wider themes that emerge from this research. These are not so much focused on action at individual campus level, but refer more widely to change which must occur nationally and internationally. The themes that follow in this section of the paper articulate a call for action at a global level.

\subsection{Need for National and International Cross-pollination Within UDL Scholarship}

A sad observation emerging from the last decade of work around UDL in HE, is that institutions tend to work in an insular fashion, intent on 'reinventing the wheel'. Instead of seeing a national or international sharing of information on UDL implementation, campuses have had the tendency to remain secretive and to not openly share their practices. This is highly problematic as it slows and hinders the overall development of UDL implementation at national and international levels. It also create phenomenon of burn out among advocates and practitioners, due to the fact that significant levels of energy are expanded carrying out the foundational work, when lessons could have easily been drawn from the trajectory and the experiences of other campuses. It will be essential to see rich and wide networks developed rapidly in order to remedy this situation. It could 
take the form of emerging scholarship for example, developed specifically with a view to assist campuses who are late coming to the table and require an overview of the work having been completed by other institutions. This intentionality needs to appear in the research being published, and it has not thus far been present. This effort could also take form of simple professional development platforms where communities of practice share openly their work and findings, in order to develop a global discourse on UDL in HE, and to cement collaborative partnerships.

\subsection{Importance of Develop a New Generation of UDL Discourse: UDL 2.0 for Higher Education}

The discourse on UDL, as well as available resources, have thus far been excessively focused on impairment and disability [82]. This chapter has demonstrated that UDL is in fact beneficial to all learners, and specifically relevant to Indigenous and International students $[4,83]$. While the impact on the UDL on a wide range of non-traditional learners is now acknowledged, this has not dribbled down to the professional development material available to faculty. Over the next decade it will be essential that campuses develop UDL resources for instructors that contextualize it within the wider challenge of creating inclusive provisions for all learners. The creation of this multidisciplinary material will require the active collaboration of stakeholders who do not at present work extensively together, notably accessibility services, teaching and learning services, support services for international students, and support services for Indigenous students. Working collaboratively is likely to prove significantly complex as each of these services is staffed with personnel with very distinct perspectives, training, and theoretical perspectives. The production of UDL material for faculty that is adequate for the next decade will therefore require a shift in mindset in HE. Examples of such multidisciplinary collaboration with a view to creating UDL material for faculty PD have been offered by universities in Belgium [84].

\subsection{Developing a Continuum Approach to UDL \\ Implementation that Sees the K-12 and Post-secondary Sectors as Spectrum}

Over the last decade, the scholarship on UDL has remained distinctly fragmented between the K-12 and the post-secondary sector. So far, each sector of the educational landscape has argued that the process of UDL implementation was unique within the variables of each of the two contexts. As a result very little literature has bridged this gap and looked at UDL in an overarching manner that might highlight commonalities between the work done in schools and the efforts deployed in HE. Even within HE, there has been further fragmentation in the literature with practitioners and scholars seeing the work being carried out in community colleges around UDL, as distinct in nature and flavour. There are of course important distinctions in the ways UDL implementation is being tackled, but there are also a lot of similarities in the challenges that both sectors currently face.
Furthermore, one of the benefits of UDL - as previously discussed - is that it offers learner a framework which is applicable from early education all the way to graduate education. This is one of the great assets of UDL from a learner perspective: it no longer subjects students to repeated transitions between approaches that are inconsistent [85]. If it is this continuum that is attractive for the learner, then there is urgent pressure on educators and service providers to acknowledge this, and consider UDL scholarship and practice as a broad spectrum that should include both K-12 and post-secondary professional. This, in turn, is likely to offer dynamic momentum to the process of UDL implementation generally: there is strength in numbers and change is likely to occur faster if both sectors collaborate actively.

\subsection{Creating National Networks of Practitioners Connected by a Desire to Implement UDL in Higher Education}

In Canada particularly, which has been the context for this study, there has been very little national voice on UDL at this stage. Most of the initiatives have occurred at provincial level, or even institutional level. While there have been efforts to create professional development venues nationally [86], opportunities for UDL scholars and practitioners to connect and form networks beyond their community or their institution remain limited. Social capital represents a significant dimension of UDL development [87]. Without it, advocates quickly feel isolated and disempowered, and risk losing momentum and falling victim to implementation fatigue. It is all too frequent to see a UDL initiative take off on a campus and die a slow death as its champions move on, retire, or simply lose enthusiasm. There have been example of national and international social network gatherings for professional development purposes, particularly on Twitter [88, 89]. Over the coming decade, however, there will be an urgent need for more of these virtual communities to emerge and thrive. They are literally the engine that fuels the development and systemic implementation of UDL beyond regional boundaries and local context $[90,91]$.

\section{References}

[1] La, H., Dyjur, P., \& Bair, H. (2018) Universal design for learning in higher education. Taylor Institute for Teaching and Learning. Calgary: University of Calgary.

[2] Knarlag, K. and B. Walters, Universal Design for Learning Licence to Learn (UDLL): a European perspective on UDL (2020), The AHEAD Journal, 11.

[3] Oliveira, A., M. Munster and A. Gonçalves. (2019) Universal Design for Learning and Inclusive Education: a Systematic Review in the International Literature. RevistaBrasileira de Educação Especial, 25 (4): 675-690.

[4] Fovet, F. (2019) Not just about disability: Getting traction for UDL implementation with International Students. In: K. Novak \& S. Bracken (Eds.) Transforming Higher Education through Universal Design for Learning: An International Perspective. London: Routledge. 
[5] Fovet, F. (2020) Using Universal Design for Learning to Create Inclusive Provisions for Indigenous Students in Higher Education - Decolonizing Teaching Practices. In: L. Roberts (Ed.), Redesigning Learning, Leadership, and Indigenous Education in the 21 st Century. Hershey, PA: IGI Global.

[6] Ives, J., and M. Castillo-Montoya. (2020) First-Generation College Students as Academic Learners: A Systematic Review. Review of Educational Research, 90 (2): 139-178.

[7] Dalton, E. M., Lyner-Cleophas, M., Ferguson, B. T., \& McKenzie, J. (2019). Inclusion, universal design and universal design for learning in higher education: South Africa and the United States. African Journal of Disability, 8, 519.

[8] Center for Universal Design (1997) The principles of universal design, version 21.0. North Carolina State University: Raleigh, NC.

[9] Oswald, S. K. (2019). Breaking the Exclusionary Boundary between User Experience and Access: Steps toward Making UX Inclusive Of Users with Disabilities. Proceedings of the 37th ACM International Conference on the Design of Communication, 1-8.

[10] Aizpurua, A., Harper, S., \& Vigo, M. (2016). Exploring the relationship between web accessibility and user experience. International Journal of Human-Computer Studies, 91, 13-23.

[11] Rao, K., \&Meo, G. (2016). Using Universal Design for Learning to Design Standards-Based Lessons. SAGE Open.

[12] Bacon, K. (2014) How a little idea called Universal Design for Learning has grown to become a big idea - elastic enough to fit every kid. Harvard Ed Magazine. Retrieved from: https://www.gse.harvard.edu/news/ed/14/01/all-along.

[13] Wilson, J. (2017) Reimagining Disability and Inclusive Education through Universal Design for Learning. Disability Studies Quarterly, 37 (2).

[14] CAST (2018). UDL and the learning brain. Wakefield, MA: Author. Retrieved from

http://www.cast.org/our-work/publications/2018/udl-learningbrain-neuroscience.html.

[15] Ok, M., Rao, K, Bryant, B., \& McDougall, D. (2017) Universal Design for Learning in Pre-K to Grade 12 Classrooms: A Systematic Review of Research. Exceptionality, 25 (2), 116-138.

[16] CAST (2019) Post-secondary Institutions with UDL Initiatives. UDL on Campus. Retrieved from: http://udloncampus.cast.org/page/udl_institutions.

[17] Houghton, M. \&Fovet, F. (2012) Reframing Disability, reshaping the provision of services. Communiqué, 13 (1), 16-19.

[18] McGrath, C., Roxå, T., \&Laksov, K. (2019) Change in a culture of collegiality and consensus-seeking: a double-edged sword. Higher Education Research \& Development, 38 (5), 1001-1014.

[19] Cassell, M., \&Halaseh, O. (2014) The Impact of Unionization on University Performance. Journal of Collective Bargaining in the Academy, 6, Article 3.

[20] Fovet, F. (in print) Developing an Ecological Approach to Strategic UDL Implementation in Higher Education. Journal of Education and Teaching.
[21] Hromalik, C., Myhill, W., \& Carr, N. (2019). "ALL Faculty Should Take this": a Universal Design for Learning Training for Community College Faculty. TechTrends, 64, 1-14.

[22] Schreffler, J., Vasquez III, E., Chini, J., \& James, W. (2019) Universal Design for Learning in postsecondary STEM education for students with disabilities: a systematic literature review. International Journal of STEM Education, 6, 8.

[23] Tobin, T. J. (2019). Reaching all learners through their phones and universal design for learning. Journal of Adult Learning, Knowledge and Innovation JALKI, 1-11.

[24] Bock, G., Gesser, M., \&Nuernberg, A. (2018). Universal Design for Learning: Scientific Production in the Period from 2011 to 2016. RevistaBrasileira de Educação Especial, 24 (1), 143-160.

[25] Song, Y. (2016) To what extent is Universal Design for Learning "universal"? A case study in township special needs schools in South Africa. Disability and the Global South, 3 (1), 910-929.

[26] Fovet, F. (2017) Access, Universal Design and Sustainability of Teaching Practices: a Powerful Synchronicity of Concepts at a Crucial Conjuncture for Higher Education. Indonesian Journal of Disability Studies (IJDS), 4 (2), 118-129.

[27] Dall'Alba, G. (2009). Phenomenology and education: An introduction. Educational Philosophy and Theory, 41 (1), 7-9.

[28] Lynch, S., \& Kuntz, A. (2019) 'A critical autoethnography of a doctoral students' research journey: learning to take risks in the academy'. Curriculum Studies in Health and Physical Education, 10 (2), 156-171.

[29] Kennette, L., \& Wilson, A. (2019) Universal Design for Learning (UDL): What is it and how do I implement it?Transformative Dialogues: Teaching \& Learning Journal, $12(1)$.

[30] Berggren, U. J., Rowan, D., Bergbäck, E., \& Blomberg, B. (2016). Disabled students' experiences of higher education in Sweden, the Czech Republic, and the United States - a comparative institutional analysis. Disability \& Society, 31, $1-18$.

[31] Svensson, I., Nordström, T., Lindeblad, E., Gustafson, S., Björn M., Sand, C., Almgren/Bäck, G., \& Nilsson, S. (2019) Effects of assistive technology for students with reading and writing disabilities. Disability and Rehabilitation: Assistive Technology.

[32] Ismail, A., \&Kuppusamy, K. S. (2019) Web accessibility investigation and identification of major issues of higher education websites with statistical measures: A case study of college websites. Journal of King Saud University - Computer and Information Sciences.

[33] Washington, G. Y. (2019). The Learning Management System Matters in Face-to-Face Higher Education Courses. Journal of Educational Technology Systems, 48 (2), 255-275.

[34] Fovet, F. (2018) Making do with what we have: using the built in functions of a Learning Management System to implement UDL. The AHEAD Journal, 7, 1-17.

[35] Hollingshead, A., \& Carr-Chellman, D. (2019, February) Engaging Learners in Online Environments Utilizing Universal Design for Learning Principles. E-Learn Magazine. Retrieved from: https://elearnmag.acm.org/featured.cfm?aid=3310383. 
[36] O'Neil, G. (2017). It's not fair! Students and staff views on the equity of the procedures and outcomes of students' choice of assessment methods. Irish Educational Studies, 36 (2), 221236.

[37] Morris, C., Milton, E., \& Goldstone, R. (2019) Case study: suggesting choice: inclusive assessment processes. Higher Education Pedagogies, 4 (1), 435-447.

[38] Spante, M., Hashemi, S., Lundin, M., \&Algers, A. (2018) Digital competence and digital literacy in higher education research: Systematic review of concept use. Cogent Education, $5(1)$.

[39] Ciesielkiewicz, M. (2019) The use of e-portfolios in higher education: From the students' perspective. Issues in Educational Research, 29 (3), 649

[40] Sewagegn, A., \&Diale, B. (2019). Empowering Learners Using Active Learning in Higher Education Institutions. In: S. Brito (Ed.) Active Learning - Beyond the Future. Intech Open. Retrieved from: https://www.intechopen.com/books/active-learning-beyond-th e-future/empowering-learners-using-active-learning-in-highereducation-institutions.

[41] Bovill, C., \& Woolmer, C. (2019) How conceptualisations of curriculum in higher education influence student-staff co-creation in and of the curriculum. Higher Education, 78, 407-422.

[42] Dollinger, M., \& Lodge, J. (2019) Student-staff co-creation in higher education: an evidence-informed model to support future design and implementation. Journal of Higher Education Policy and Management.

[43] Clack, J. (2019) Can we fix education? Living emancipatory pedagogy in Higher Education. Teaching in Higher Education.

[44] Tight, M. (2019) The neoliberal turn in Higher Education. Higher Education Quarterly, 73, 273-284.

[45] Solomonides, I. (2013). A relational and multidimensional model of student engagement. In: E. Dunne, \& D. Owen (Eds.) The student engagement handbook: Practice in higher $E$ Education, (1st ed., pp. 43-58). Bingley: Emerald.

[46] Wekullo, C. S. (2019). International undergraduate student engagement: Implications for higher education administrators. Journal of International Students, 9 (1), 320-337.

[47] Zepke, N. (2018). Student engagement in neo-liberal times: What is missing? Higher Education Research and Development, 37 (2), 433-446.

[48] Bond, M., Buntins, K., Bedenlier, S., Zawacki-Richter, O., \&Kerres, M. (2020) Mapping research in student engagement and educational technology in higher education: a systematic evidence map. International Journal of Educational Technology Higher Education, 17, 2.

[49] Bedrossian, L. (2018), Understand and promote use of Universal Design for Learning in higher education. Disability Compliance for Higher Education, 23, 7-7.

[50] Leslie, H. J. (2019) Trifecta of Student Engagement: A framework for an online teaching professional development course for faculty in higher education. Journal of Research in Innovative Teaching \& Learning.

[51] Serrano, M. M., O’Brien, M., Roberts, K., \& Whyte, D. (2018). Critical Pedagogy and assessment in higher education: The ideal of 'authenticity' in learning. Active Learning in Higher Education, 19 (1), 9-21.

[52] Sanger C. S. (2020) Inclusive Pedagogy and Universal Design Approaches for Diverse Learning Environments. In: Sanger C., Gleason N. (eds) Diversity and Inclusion in Global Higher Education. Palgrave Macmillan, Singapore.

[53] Seok, S., DaCosta, B., \& Hodges, R. (2018). A Systematic Review of Empirically Based Universal Design for Learning: Implementation and Effectiveness of Universal Design in Education for Students with and without Disabilities at the Postsecondary Level. Open Journal of Social Sciences, 6, 171-189.

[54] Capp, M. (2017) The effectiveness of universal design for learning: a meta-analysis of literature between 2013 and 2016. International Journal of Inclusive Education, 21 (8), 791-807.

[55] Fovet, F. (2020) Using Universal Design for Learning to optimize flexibility in assessment and class activities while maximizing alignment with course objectives. In: Y. Inoue-Smith \& T. McVey (Eds.) Optimizing Higher Education Learning Through Activities and Assessments. IGI Global: Hershey, PA.

[56] Kumar, K., \&Wideman, M. (2014) Accessible by design: Applying UDL principles in a first year undergraduate course. Canadian Journal of Higher Education/Revue canadienned'enseignementsupérieur, 44 (1), 125-147.

[57] Miller, D., \& Lang, P. (2016) Using the Universal Design for Learning Approach in Science Laboratories To Minimize Student Stress. Journal of Chemical Education, 93 (11), 1823-1828.

[58] Thurber, A., \& Bandy, J. (2018) Creating Accessible Learning Environments. Retrieved from http://cft.vanderbilt.edu/guides-sub-pages/creating-accessiblelearning-environments/.

[59] Coleman, S., \& Smith, C. (2019) Evaluating the benefits of virtual training for bioscience students. Higher Education Pedagogies, 4 (1), 287-299.

[60] Bonaccio, S., Connelly, C. E., Gellatly, I. R., Jetha, A., \&Ginis, K. (2019) The Participation of People with Disabilities in the Workplace Across the Employment Cycle: Employer Concerns and Research Evidence. Journal of Business and Psychology, $35,135-158$.

[61] St Esprit, M. (2019, March 6) The Stigma of Choosing Trade School Over College. The Atlantic. Retrieved from: https://www.theatlantic.com/education/archive/2019/03/choos ing-trade-school-over-college/584275/.

[62] Bartlett, M., \& Ehrlich, S. (2020) How a Universal Design Mindset Can Support Learning in the Workplace. The AHEAD Journal. Retrieved from:

https://www.ahead.ie/journal/How-a-Universal-Design-Minds et-Can-Support-Learning-in-the-Workplace.

[63] Chorazy, M., \&Klinedinst, K. (2019) Learn by Doing: A Model for Incorporating High-Impact Experiential Learning Into an Undergraduate Public Health Curriculum. Frontiers in Public Health, 7.

[64] Niagara College (2019) Determining Instructional Strategies for EL. Experiential Learning Toolkit. Retrieved from: https://www.eltoolkit.ca/delivering-experiential-learning-oppo rtunities/determining-instructional-strategies-for-el/. 
[65] Glass, D., Meyer, A., \& Rose, D. (2013). Universal Design for Learning and the Arts. Harvard Educational Review, 83, 98-119.

[66] Malley, S. (2014). Students with disabilities and the core art standards: Guiding principles for teachers. The John F. Kennedy Center for the Performing Arts.

[67] Fountain, H. (2014). Differentiated instruction in art. Worchester, MA: Davis.

[68] Barrett, T. (2000). Studio Critiques of Student Art: As They Are, as They Could Be with Mentoring. Theory Into Practice, 39 (1), 29-35

[69] Scagnetti, G. (2017) A dialogical model for studio critiques in Design Education. The Design Journal, 20 (1), S781-S791.

[70] Geschwind, L. (2019) Legitimizing Change in Higher Education: Exploring the Rationales Behind Major Organizational Restructuring. Higher Education Policy, 32, 381-395.

[71] Stensaker, B. (2015) Organizational identity as a concept for understanding university dynamics. Higher Education 69 (1), 103-115.

[72] Kezar, A. (2013) Understanding sensemaking/sensegiving in transformational change processes from the bottom up. Higher Education, 65 (6), 761-780.

[73] Mathews, K. (2018) Growing Our Own: Cultivating Faculty Leadership. Change: The Magazine of Higher Learning, 50 (3-4), 88-92.

[74] Gorham, J., \& Roberts, B. (2014, August 6) You need to know about universal design for learning. University Affairs. Retrieved from: https://www.universityaffairs.ca/opinion/in-my-opinion/you-n eed-to-know-about-universal-design-for-learning/.

[75] Surtees, V. (2019). Challenging Deficit Constructions of the International Student Category in Canadian Higher Education. TESL Canada Journal, 36 (1), 48-70.

[76] Kieran, L., \& Anderson, C. (2019). Connecting Universal Design for Learning with Culturally Responsive Teaching. Education and Urban Society, 51 (9), 1202-1216.

[77] Evans, T., Bira, L., Gastelum, J., Weiss, T., \&Vanderford, N. (2018) Evidence for a mental health crisis in graduate education. Nature Biotechnology, 36, 282-284.

[78] Terras, K., \& Phillips, A. (2015) Disability Accommodations in Online Courses: The Graduate Student Experience. Journal of Postsecondary Education and Disability, 28 (3), 329-340 329.

[79] Johnstone, C., \& Edwards, P. (2020). Accommodations, Accessibility, and Culture: Increasing Access to Study Abroad for Students With Disabilities. Journal of Studies in International Education, 24 (4), 424-439.

[80] Smith, S. J., Rao, K., Lowrey, K. A., Gardner, J. E., Moore, E., Coy, K.,... Wojcik, B. (2019). Recommendations for a National Research Agenda in UDL: Outcomes From the UDL-IRN Preconference on Research. Journal of Disability Policy Studies, 30 (3), 174-185.

[81] Geerlings L., \& Lundberg, A. (2018) Global discourses and power/knowledge: theoretical reflections on futures of higher education during the rise of Asia. Asia Pacific Journal of Education, 38 (2), 229-240.

[82] Nieminen, J., \&Pesonen, H. (2020) Taking Universal Design Back to Its Roots: Perspectives on Accessibility and Identity in Undergraduate Mathematics. Education Sciences, 10 (1), 12.

[83] Gray, E., Hogan, L., \& Benton, D. (2019) A practical approach to UDL. Paper presented at the Chiefs of Ontario Sharing Forum. Toronto, April.

[84] SIHO (2020) New inclusive mobility project. Retrieved from: https://www.siho.be/en/new-inclusive-mobility-project.

[85] Fovet, F. (2014) Navigating the delicate emerging synchronicity between inclusion and access. LEARNing Landscapes, 7 (2), 17-24.

[86] Third Pan-Canadian Conference on UDL (2019) Connecting the Dots - Sharing Promising Practices across Country. http://www.udlcanada.ca/index.html.

[87] Lightfoot M. (2016) The Emergence of Digital Social Capital in Education. In: Haslam I. R., Khine M. S. (Eds) Leveraging Social Capital in Systemic Education Reform. Contemporary Approaches to Research in learning Innovations. SensePublishers, Rotterdam.

[88] CAST (2020) \#udlchat. Retrieved from: https://twitter.com/hashtag/udlchat?lang=en.

[89] Flood, M. (2020) \#UDLchatIE. Retrieved from: https://twitter.com/hashtag/UDLchatIE?src=hashtag_click.

[90] Greenhow, C., Campbell, D., Galvin, S. \&amp; Askari, E. (2018). Social Media in Teacher Professional Development: A Literature Review. In E. Langran\&amp; J. Borup (Eds.), Proceedings of Society for Information Technology \& Teacher Education International Conference (pp. 2256-2264). Washington, D. C., United States: Association for the Advancement of Computing in Education (AACE).

[91] Bruguera, C., Guitert, M., \& Romeu, T. (2019). Social media and professional development: a systematic review. Research in Learning Technology, 27. 